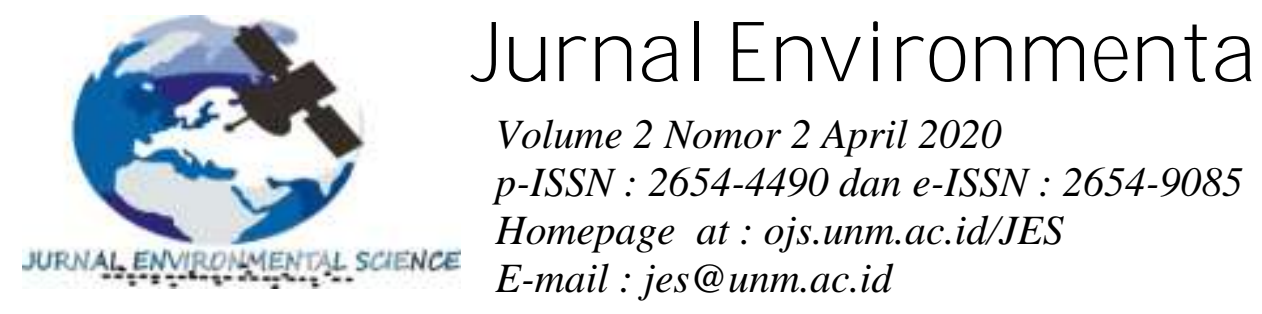

\title{
PENGEMBANGAN OBJEK WISATA PANTAI SUNARI DI KECAMATAN BONTOSIKUYU, KABUPATEN KEPULAUAN SELAYAR
}

\author{
Nur Najmi ${ }^{1}$, Maddatuang ${ }^{2}$, M. Nur Zakariah Leo ${ }^{3}$ \\ Jurusan Geografi, Fakultas Matematika dan Ilmu Pengetahuan Alam, \\ Universitas Negeri Makassar, Indonesia. \\ Email: nurnajmipramadana@gmail.com ${ }^{I}$
}

\begin{abstract}
This study aims to find out 1). To find out the inhibiting and supporting factors in developing the Sunari Beach tourism object in Bontosikuyu District, Selayar Islands Regency. 2). To find out the development strategy of Sunari Beach tourism object in Bontosikuyu District, Selayar Islands Regency. The collection of data using the method of observation, interviews and documentation. The sampling technique is accidental sampling. While for data analysis using descriptive analysis and SWOT analysis. Descriptive analysis is used to describe supporting and inhibiting factors in developing Sunari Beach tourism objects and SWOT analysis is used to find out strategies that can be done in the effort to develop Sunari Beach tourism object. SWOT analysis is also used to compare internal factors of strengths and weaknesses with external factors of opportunities and threats possessed by Sunari Beach attractions. The results of the study show that: the supporting factors that exist in the sunari beach attractions are the pristine, beautiful and comfortable natural scenery, the availability of vacant land, the support of the community, the easy level of accessibility, and good security conditions. The inhibiting factors are limited budget, promotion of tourism objects that have not been maximized, lack of professionals, no cooperation with the government, lack of awareness of visitors in maintaining cleanliness
\end{abstract}

Keywords: Sunari Beach, Development Strategy,SWOT Analysis

\begin{abstract}
ABSTRAK
Penelitian ini bertujuan untuk mengetahui 1). Untuk mengetahui faktor penghambat dan pendukung dalam upaya pengembangan objek wisata Pantai Sunari di Kecamatan Bontosikuyu Kabupaten Kepulauan Selayar.2). Untuk mengetahui strategi pengembangan objek wisata Pantai Sunari di Kecamatan Bontosikuyu Kabupaten Kepulauan Selayar. Adapun pengumpulan data dengan menggunakan metode observasi, wawancara dan dokumentasi. Teknik pengambilan sampel yaitu accidental sampling. Sedangkan untuk analisis data menggunakan analisis deskriptif dan analisis SWOT. Analisis deskriptif digunakan untuk mendeskriipsikan faktor pendukung dan penghambat dalam upaya pengembangan objek wisata Pantai Sunari dan analisis SWOT digunakan untuk mengetahui strategi yang dapat dilakukan dalam upaya pengembangan objek wisata Pantai Sunari. Analisis SWOT juga digunakan untuk membandingkan antara faktor internal kekuatan dan kelemahan dengan faktor eksternal peluang dan ancaman yang dimiliki oleh objek wisata Pantai Sunari. Hasil penelitian menunjukkan bahwa : faktor pendukung yang ada pada objek wisata pantai sunari yaitu pemandangan alam yang masih asli, tersedianya lahan kosong, adanya dukungan dari masyarakat, tingkat aksesibilitas yang mudah, dan kondisi keamanan yang baik. Adapun faktor penghambat yaitu keterbatasan anggaran, promosi objek wisata yang belum maksimal, kurangnya tenaga profesional, belum ada kerjasama dengan pemerintah, kurangnya kesadaran para pengunjung dalam menjaga kebersihan
\end{abstract}

Kata Kunci : Pantai Sunari, Strategi Pengembangan,Analisis SWOT 


\section{PENDAHULUAN}

Pariwisata merupakan sektor yang bisa menjunjung kemajuan suatu daerah, terutama dengan adanya peraturan mengenai adanya peraturan mengenai otonomi daerah. Kegiatan ini diberlakukan salah satunya atas dasar karena masyarakat daerah memiliki modal yang dapat diandalkan untuk kemajuan daerahnya, salah satunya adalah melalui kegiatan pariwisata (Amdani, 2008).

Berdasarkan Pasal 4 Undang-Undang Nomor 33 Tahun 2009 Tentang Kepariwisataan dapat diketahui bahwa pariwisata bertujuan untuk meningkatkan pertumbuhan ekonomi, meningkatkan kesejahteraan rakyat, menghapus kemiskinan, mengatasi pengangguran, melestarikan alam,lingkungan dan sumber daya, memajukan kebudayaan, mengangkat citrabangsa, memupuk rasa cinta tanah air, memperkukuh jati diri dan kesatuanbangsa, mempererat persahabatan antarbangsa

Kabupaten Kepulauan Selayar merupakan salah satu kabupaten yang ada di sulawesi selatan yang memiliki beberapa objek wisata yang bagus dan menarik. Potensi wisata di Kabupaten kepulauan selayar cukup banyak meliputi wisata budaya, wisata sejarah, wisata alam dan wisata bahari.. Salah satunya adalah objek wisata Pantai Sunari yang terletak dikecamatan bontosikuyu. Pantai sunari adalah salah satu pantai yang ada di Kabupaten Kepulauan Selayar yang laut dan pantainya lumayan terawat. Di pantai ini dilengkapi hamparan pasir dan air laut yang bening serta pantai ini juga memiliki pemandangan sore yang indah yang bisa membuat para pengunjung ataupun wisatawan betah untuk berlama-lama dan juga terdapat beberapa tempat yang dapat dijadikan spot foto. Akan tetapi pada saat musim hujan jumlah pengunjung baik lokal maupun non lokal mengalami penurunan dari hari biasanya, dikarenakan akses jalan dalam lingkup pantai terendam air hujan dan juga masih kurangnya fasilitas yang tersedia seperti wc umum dan tempat berteduh bagi pengunjung untuk menikmati panorama pantai sehingga diperlukan peran pemerintah daerah agar secepatnya dapat melakukan upaya pengembangan objek Wisata Pantai Sunari agar tidak menjadi daerah tertinggal. Pantai Sunari memiliki luas wilayah \pm 3 ha.

\section{METODE}

Penelitian ini dilaksanakan di Pantai Sunari Desa Patikarya Kecamatan Bontosikuyu Kabupaten Kepulauan Selayar pada bulan Mei - Juli 2019. Sampel dipilih menggunakan metode purposive sampling atau sampel bertujuan dan metode accidental sampling( pengambilan sampel secara kebetulan. Untuk penelitian ini jumlah sampel yang didapatkan berdasarkan jumlah pengunjung atau respnden yang ditemui pada saat melakukan penelitian ini yakni (1) teknik observasi, teknik ini dilakukan dengan melakukan pengamatan langsung di lapangan untuk mendapatkan gambaran umum dan data mengenai kondisi Pantai Sunari, (2) teknik wawancara, teknik wawancara dilakukan dengan menggunakan beberapa daftar pertnyaan yang dibuat sebelumnya, mulai dari data pribadi responden, tingkat pendidikan jenis pekerjaan, pendapatan responden per bulan, kendaraan yang dipakai menuju objek wisata sampai pada pertanyaan mengenai pengembangan objek wisata pantai sunari serta harapanharapan responden terkait perkembangan objek wisata pantai sunari di masa yang akan datang.(3) teknik dokumentasi, teknik dokumentasi yaitu pengumpulan data sekunder dari instansi terkait melalui dokumentasi, juga perekaman kondisi alam seperti panorama pantai yang berada di kawasan Pantai Sunari dan hal-hal yang juga dianggap mendukung dalam kegiatan penelitian ini. Adapun teknik analisis data pada penelitian ini yakni

1) Metode Analisis Deskriptif

Penelitian ini bersifat deskriptif dimana penelitian ini merupakan rangkaian dari hasil observasi, wawancara serta dokumentasi yang dilakukan dilapangan. Dari penelitian deskriptif dapat diperoleh data tentang faktor-faktor apa aja yang menjadi penghambat dan pendukung dalam pengembangan objek wisata pantai sunari.

2) Metode Analisis SWOT

Menurut Rangkuti (2006 : 22) sebelum merumuskan matriks SWOT untuk strategi pengembangan objek wisata Pantai Sunari, maka terlebih dahulu membuat matriks terkait strategi faktor internal dan eksternal.

a) Cara penentuan faktor strategi eksternal (EFAS)

i. Susunlah dalam kolom 1 (5 sampai dengan 10 peluang dan ancaman). 
ii. Beri bobot masing-masing faktor dalam kolom 2, mulai dari 1,0 (sangat penting) sampai dengan 0,0 (tidak penting).

iii. Hitung rating (dalam kolom 3) untuk masing-masing faktor dengan memberikan skala mulai dari 4 (outstanding) sampai dengan 1 (poor) berdasarkan pengaruh tersebut terhadap kondisi perusahaan yang bersangkutan. Pemberian nilai rating untuk faktor peluang bersifat positif (peluang yang semakin besar diberi rating 4, tetapi jika peluangnya kecil diberi rating 1).

iv. Kalikan bobot pada kolom 2 dengan rating pada kolom 3, untuk memperoleh faktor pembobotan kolom 4.

v. Cara penentuan faktor strategi internal (IFAS)

\section{HASIL DAN PEMBAHASAN}

Hasil

Tabel 1 Mean kekuatan dalam pengembangan objek wisata Pantai Sunari

\begin{tabular}{clcl}
\hline No & \multicolumn{1}{c}{ Kekuatan } & Mean & \multicolumn{1}{c}{ Keterangan } \\
\hline 1 & Memiliki spot foto yang menarik & 3.7 & Sangat Tinggi \\
\hline 2 & Tingkat aksesibilitas yang mudah & 3.1 & Tinggi \\
\hline 3 & Retribusi yang tidak terlalu mahal & 3.25 & Tinggi \\
\hline 4 & Kondisi keamanan yang baik & 3.08 & Tinggi \\
\hline 5 & Area sekitar pantai sunari yang luas & 3.3 & Sangat Tinggi \\
\hline & Mean & 3.3 & Sangat Tinggi \\
\hline
\end{tabular}

Sumber : Data Hasil Olah Data Kuisioner Tahun 2019

Tabel 2 Mean kelemahan dalam pengembangan objek wisata Pantai Sunari

\begin{tabular}{cllll}
\hline No & Kelemahan & \multicolumn{2}{l}{ Mean } & Keterangan \\
\hline 1 & $\begin{array}{l}\text { Ketersediaan makanan terbatas dengan } \\
\text { harga yang relatif mahal }\end{array}$ & 1.9 & Tinggi \\
\hline 2 & $\begin{array}{l}\text { Kurangnya tenaga profesional dalam } \\
\text { mengolah pantai }\end{array}$ & 1.73 & Sangat Tinggi \\
\hline 3 & $\begin{array}{l}\text { Promosi terkait pantai sunari yang } \\
\text { belum maksimal }\end{array}$ & 1.9 & Tinggi \\
\hline 4 & $\begin{array}{l}\text { Keterbatasan anggaran untuk biaya } \\
\text { sarana dan prasarana yang belum } \\
\text { lengkap }\end{array}$ & 1.7 & Sangat Tinggi \\
\hline 5 & $\begin{array}{l}\text { Kesadaran pengunjung terkait } \\
\text { pentingnya menjaga kelestarian } \\
\text { lingkungan yang masih kurang }\end{array}$ & 1.8 & Tinggi \\
\hline & Mean
\end{tabular}

Sumber : Data Hasil Olah Data Kuisioner Tahun 2019

Tabel 3 Mean Peluang dalam pengembangan objek wisata Pantai Sunari

\begin{tabular}{clllc}
\hline No & \multicolumn{1}{c}{ Peluang } & Mean & Keterangan \\
\hline \multicolumn{1}{c}{$\begin{array}{l}\text { Semakin berkembangnya media sosial sekarang } \\
\text { ini yang bisa dimanfaatkan oleh pihak } \\
\text { pengelolah dalam usaha mempromosikan objek } \\
\text { wisata pantai sunari }\end{array}$} & S.7 & Sangat Tinggi \\
\hline 2 & $\begin{array}{l}\text { Meningkatkan jumlah wisatawan yang akan } \\
\text { berkunjung }\end{array}$ & Tinggi \\
\hline 3 & $\begin{array}{l}\text { Rencana pengembangan objek wisata oleh } \\
\text { pemerintah setempat }\end{array}$ & Tinggi \\
\hline 4 & $\begin{array}{l}\text { Pemerintah yang berwenang memberikan } \\
\text { peluang bagi pengelola terkait ataupun } \\
\text { masyarakat dalam upaya pengembangan objek }\end{array}$ & Sangat Tinggi \\
\hline
\end{tabular}


wisata

\begin{tabular}{rrr}
\hline Mean & 3.4 & Sangat Tinggi
\end{tabular}

Sumber : Data Hasil Olah Data Kuisioner Tahun 2019

Tabel 4 Mean Ancaman dalam pengembangan objek wisata Pantai Sunari

\begin{tabular}{cllcc}
\hline No & \multicolumn{2}{c}{ Ancaman } & Mean & Keterangan \\
\hline 1 & $\begin{array}{l}\text { Adanya objek wisata lain didekat pantai } \\
\text { sunari }\end{array}$ & 1.8 & Tinggi \\
\hline 2 & $\begin{array}{l}\text { Kesadaran pengunjung dalam menjaga } \\
\text { kebersihan pantai sunari }\end{array}$ & 1.9 & Tinggi \\
\hline 3 & Kurangnya dukungan pemerintah & & 1.7 & Sangat Tinggi \\
\hline 4 & Kerusakan lingkungan & 1.6 & Sangat Tinggi \\
\hline \multicolumn{2}{c}{ Mean } & 1.8 & Tinggi \\
\hline
\end{tabular}

Sumber : Data Hasil Olah Data Kuisioner Tahun 2019

Tabel 5 Matriks Analisis SWOT

\begin{tabular}{|c|c|c|}
\hline Faktor Internal & $\begin{array}{l}\text { STRENGTHS/ } \\
\text { KEKUATAN } \\
\text { 1. Memiliki spot foto } \\
\text { yang menarik } \\
\text { 2. Tingkat aksesibilitas } \\
\text { yang mudah } \\
\text { 3. Retribusi yang tidak } \\
\text { terlalu mahal } \\
\text { 4. Kondisi keamanan } \\
\text { yang baik } \\
\text { 5. Area sekitar pantai } \\
\text { yang luas }\end{array}$ & $\begin{array}{l}\text { WEAKNESSES/ } \\
\text { KELEMAHAN } \\
\text { 1. Ketersediaan makanan } \\
\text { terbatas dengan harga } \\
\text { yang relatif mahal } \\
\text { 2. Kurangnya tenaga } \\
\text { profesional dalam } \\
\text { mengelola pantai } \\
\text { 3. Promosi terkait pantai } \\
\text { sunari yang belum } \\
\text { maksimal } \\
\text { 4. Keterbatasan anggaran } \\
\text { untuk biaya sarana dan } \\
\text { prasarana yang belum } \\
\text { lengkap pang } \\
\text { 5. Kesadaran pengunjung } \\
\text { terkait pentingnya } \\
\text { menjaga kebersihan } \\
\text { lingkungan yang masih } \\
\text { kurang }\end{array}$ \\
\hline $\begin{array}{l}\text { OPPORTUNITIES/ } \\
\text { PELUANG } \\
\text { 1. Semakin } \\
\text { FaktorEksternal } \\
\text { sekarang iniyang } \\
\text { bisa dimanfaatkan } \\
\text { oleh pihak pengelola } \\
\text { dalam usaha } \\
\text { mempromosikan } \\
\text { objek wisata pantai } \\
\text { sunari a a } \\
\text { Meningkatnya } \\
\text { jumlah wisatawan } \\
\text { yang akan } \\
\text { berkunjung } \\
\text { 3. Rencana }\end{array}$ & $\begin{array}{l}\text { STRATEGI S-O } \\
\text { 1. Meningkatkan objek } \\
\text { wisata yang dimiliki } \\
\text { pantai sunari karena } \\
\text { memiliki pemandangan } \\
\text { yang menarik untuk } \\
\text { dijadikan sebagai spot } \\
\text { foto. } \\
\text { 2. Meningkatkan } \\
\text { keamanan pantai sunari } \\
\text { dengan tujuan menarik } \\
\text { wisatawan yang akan } \\
\text { berkunjung yang } \\
\text { didukung dengan } \\
\text { tingkat aksesibilitas } \\
\text { yang mudah dan biaya } \\
\text { retribusi yang tidak }\end{array}$ & $\begin{array}{l}\text { STRATEGI W-O } \\
\text { 1. Untuk mengembangkan } \\
\text { objek wisata Pantai } \\
\text { Sunari dibutuhkan } \\
\text { dukungan dari dinas } \\
\text { pariwisata } \\
\text { mengatasi keterbatasan } \\
\text { anggaran pengelola } \\
\text { obyek wisata Pantai } \\
\text { Sunari. } \\
\text { 2. Meningkatkan sarana } \\
\text { dan prasarana obyek } \\
\text { wisata Pantai Sunari } \\
\text { untuk meningkatkan } \\
\text { jumlah wisatawan yang } \\
\text { akan berkunjung. } \\
\text { 3. Memperluas promosi }\end{array}$ \\
\hline
\end{tabular}




\begin{tabular}{|c|c|c|c|}
\hline $\begin{array}{l}\text { pengembangan } \\
\text { objek wisata oleh } \\
\text { pemerintah setempat } \\
\text { 4. } \\
\text { Pemerintah yang } \\
\text { berwenang } \\
\text { memberikan peluang } \\
\text { bagi pengelola } \\
\text { terkait atau } \\
\text { masyarakat dalam } \\
\text { upaya a a } \\
\text { pengembangan } \\
\text { objek wisata }\end{array}$ & 3. & \begin{tabular}{lr}
\multicolumn{2}{l}{ terlalu mahal. } \\
Memanfaatkan lahan \\
yang kosong untuk \\
membangun sarana dan \\
prasarana & yang \\
bertujuan & untuk \\
memfasilitasi & \\
antusisiasme & \\
pengunjung yang \\
datang ke objek & wisata \\
\multicolumn{2}{l}{ pantai sunari. }
\end{tabular} & $\begin{array}{lr}\text { obyek wisata } & \text { Pantai } \\
\text { Sunari diberbagai media } \\
\text { agar dapat } & \text { menarik } \\
\text { banyak pengunjung } \\
\text { seiring rengan } \\
\text { berkembangnya } & \text { obyek } \\
\text { wisata lain } & \text { yang } \\
\text { mengakibatkan } & \text { adanya } \\
\text { persaingan. } & \end{array}$ \\
\hline $\begin{array}{l}\text { ANCAMAN/ } \\
\text { THREATS } \\
\text { 1. Adanya objek wisata } \\
\text { lain didekat pantai } \\
\text { sunari } \\
\text { 2. Kesadaran } \\
\text { pengunjung dalam } \\
\text { menjaga kebersihan } \\
\text { pantai sunari } \\
\text { 3. Kurangnya } \\
\text { dukungan } \\
\text { pemerintah } \\
\text { 4. Kerusakan } \\
\text { lingkungan }\end{array}$ & & 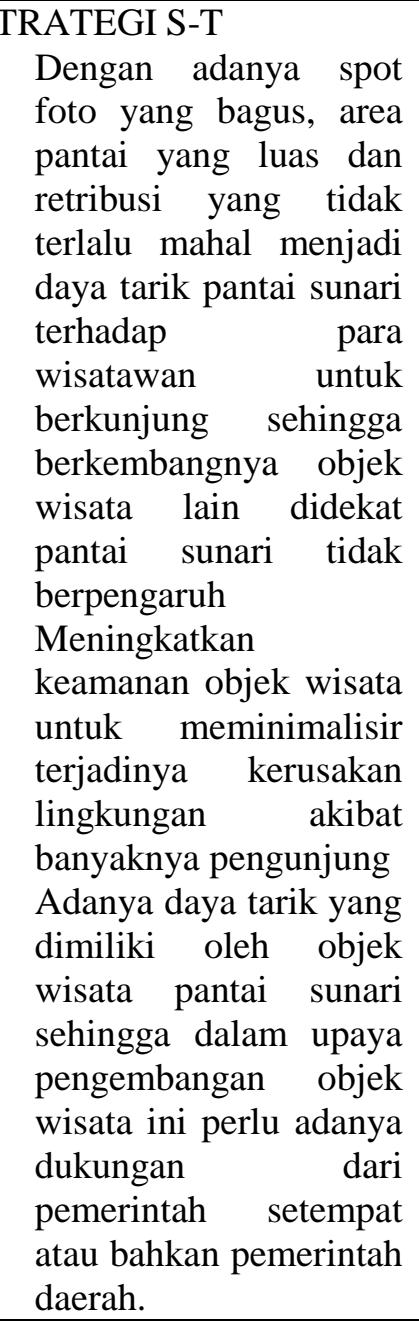 & 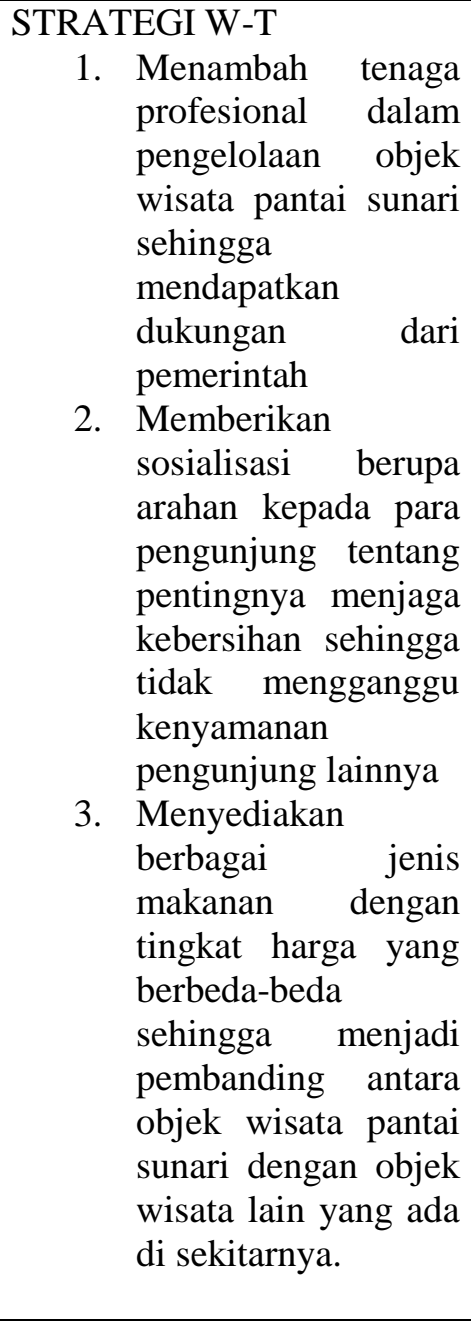 \\
\hline
\end{tabular}

Sumber : Hasil Olah Data Kuisioner, Tahun 2019

Berdasarkan kekuatan, kelemahan, peluang dan ancaman yang dimiliki oleh Pantai Sunari maka diperoleh strategi yang dapat dilakukan oleh pengelola dalam upaya pengembangan objek wisata Pantai Sunari yaitu sebagai berikut :

1) Meningkatkan objek wisata yang dimiliki pantai sunari karena memiliki pemandangan yang menarik untuk dijadikan sebagai spot foto, area pantai sunari yang luas, tingkat aksesibilitas yang mudah, kondisi keamanan yang baik,dan retribusi yang tidak terlalu mahal

2) Memanfaatkan lahan yang kosong untuk membangun sarana dan prasarana yang bertujuan untuk memfasilitasi antusisiasme pengunjung yang datang ke objek wisata pantai sunari.

3) Meningkatkan keamanan pantai sunari dengan tujuan menarik wisatawan yang akan berkunjung yang didukung dengan tingkat aksesibilitas yang mudah dan biaya retribusi yang tidak terlalu mahal. 


\section{Pembahasan}

\section{Faktor Pendukung Dan Penghambat Pengembangan Objek Wisata Pantai Sunari}

Faktor pendukung pertama, yakni Pemandangan alam yang masih asli, indah dan nyaman. faktor pendukung kedua, yaitu masih tersedianya lahan kosong. Yang ketiga, yaitu Adanya dukungan dari masyarakat sekitar dalam upaya pengembangan objek wisata Pantai Sunari. Yang keempat ,tingkat aksesibilitas yang mudah. Yang kelima, Kondisi keamanan yang baik. Kondisi keamanan yang baik dilokasi objek wisata merupakan faktor penting dalam upaya pengembangannya.

Faktor penghambat dalam upaya pengembangan objek wisata pantai sunari yaitu yang pertama, Keterbatasan Anggaran untuk Biaya Pembenahan Sarana dan Prasarana yang ada di Objek Wisata Pantai Sunari. Yang kedua, kondisi jalan masuk menuju area objek wisata Pantai Sunari yang masih kurang baik. Yang ketiga, promosi objek wisata yang belum maksimal. Pantai Sunari merupakan salah satu objek wisata baru yang ada di Kabupaten Kepulauan Selayar. Yang keempat, kurangnya tenaga kerja profesional dalam pengelolaan objek wisata. Dan yang terakhir belum adanya kerja sama dengan pemerintah terkait pegelolaan objek wisata pantai sunari serta kurangnya kesadaran para pengunjung dalam menjaga kebersihan pantai sunari.

\section{Strategi pengembangan objek wisata pantai sunari}

Strategi pengembangan yang dapat dilakukan dalam upaya pengembangan objek wisata pantai sunari yang pertama yaitu meningkatkan objek wisata yang dimiliki pantai sunari karena memiliki pemandangan yang menarik untuk dijadikan sebagai spot foto, area pantai sunari yang luas, tingkat aksesibilitas yang mudah, kondisi keamanan yang baik,dan retribusi yang tidak terlalu mahal. Yang kedua yaitu memanfaatkan lahan yang kosong untuk membangun sarana dan prasarana yang bertujuan untuk memfasilitasi antusiasme pengunjung yang datang ke objek wisata pantai sunari. Dan yang ketiga meningkatkan keamanan pantai sunari dengan tujuan menarik wisatawan yang akan berkunjung yang didukung dengan tingkat aksesibilitas yang mudah dan biaya retribusi yang tidak terlalu mahal.

\section{SIMPULAN DAN SARAN}

Berdasarkan hasil penelitian dan pembahasan dapat disimpulkan bahwa : Faktor pendukung pengembangan objek wisata pantai Sunari yaitu pemandangan alam yang masih asli, indah dan nyaman, masih tersedianya lahan kosong, adanya dukungan dari masyarakat sekitar dalam upaya pengembangan objek wisata pantai sunari, tingkat aksesibilitas yang mudah, dan kondisi keamanan yang baik. Adapun faktor penghambat yaitu keterbatasan anggaran untuk biaya pembenahan saranadan prasarana yang ada di objek wisata pantai sunari, kondisi jalan masuk meuju area objek wisata yang masih kurang baik, promosi objek wisata yang belum maksimal, kurangnya tenaga profesional dalam pengelolaan objek wisata, belum ada kerjasama dengan pemerintah, kurangnya kesadaran para pengunjung dalam menjaga kebersihan diwilayah pantai sunari.

Strategi pengembangan yang dapat dilakukan dalam upaya pengembangan objek wisata pantai sunari yang pertama yaitu meningkatkan objek wisata yang dimiliki pantai sunari karena memiliki pemandangan yang menarik untuk dijadikan sebagai spot foto, area pantai sunari yang luas, tingkat aksesibilitas yang mudah, kondisi keamanan yang baik,dan retribusi yang tidak terlalu mahal. Yang kedua yaitu memanfaatkan lahan yang kosong untuk membangun sarana dan prasarana yang bertujuan untuk memfasilitasi antusiasme pengunjung yang datang ke objek wisata pantai sunari. Dan yang ketiga meningkatkan keamanan pantai sunari dengan tujuan menarik wisatawan yang akan berkunjung yang didukung dengan tingkat aksesibilitas yang mudah dan biaya retribusi yang tidak terlalu mahal.

Berdasarkan hasil penelitian dan kesimpulan maka dapat dikemukakan beberapa saran yang mungkin dapa menjadi perhatian semua pihak di dalam upaya pengembangan objek wisata Pantai Sunari yaitu sebagai berikut : (1) Pemerintah daerah, dinas pariwisata, ataupun pemerintah setempat diharapkan mampu memberikan dukungan atau perhatian untuk objek wisata Pantai Sunari dengan membuat kebijakan-kebijakan yang sesuai dengan upaya pengembangan objek wisata Pantai Sunari,

(2) Diharapkan kepada pengelolah objek wisata Pantai Sunari untuk lebih meningkatkan pelayanan yang baik dan nyaman kepada para pengunjung dengan melengkapi beberapa kekurangan sarana dan prasarana yang belum memadai yang ada di area objek wisata pantai sunari serta memberikan arahan 
kepada pengunjung untuk tetap menjaga kebersihan diarea pantai sunari demi kenyamanan aktifitas para pengunjung lainnya, (3) Diharapkan kepada peneliti selanjutnya untuk mengkaji lebih dalam terkait bentuk pengembangan beberapa objek wisata yang ada di Kabupaten Kepulauan Selayar.

\section{DAFTAR RUJUKAN}

Amdani, Suut. 2008. Analisis Potensi Objek Wisata Alam Pantai di Kabupaten Gunung Kidul. Surakarta : Fakultas Geografi Universitas Muhammadiyah Surakarta.

Anindita, Melisa, 2015, “Analisa Faktor-Faktor yang Memperngaruhi Tingkat Kunjunga ke Kolam Renang Boja" Skripsi Ekonomika dan Bisnis, Universitas Diponegoro

Arikunto, Suharsimi. 2010. Prosedur Penelitian. Rineka Cipta

Jabal. 2015. Strategi Pengembangan Objek Wisata Pantai Tete Desa Bone Pute Kecamatan Tonra Kabupaten Bone. Skripsi FMIPA, UNM

Kamus Besar Bahasa Indonesia. 2014. Jakarta: Pusat Bahasa, Departemen Pendidikan Nasional Indonesia, hal. 201

Marpaung, Happy, 2002. Pengetahuan Pariwisata. Bandung. Alfabeta

Punaji, Setyosari. 2013. Metode Penelitian Pendidikan dan Pengembangan. Jakarta: Kencana Prenadamedia Group.

Undang-Undang Nomor 10 Tahun 2009 Tentang Kepariwisataan, Sekretariat Negara. Jakarta : Indonesia.

Utama, I GustiBagusRai. 2016. Pengantar Industri Pariwisata (Tantangan dan Peluang Bisnis Kreatif). Yogyakarta : Deepublish.

Ridwan, Mohammad. 2012. Perencanaan Pariwisata dan Pengembangan Pariwisata,Medan Polonia: PT. Sofmedi 